Abstract P146 Table 1 Characteristics of the population studied and comparison between patients with and without fragility fractures

\begin{tabular}{|c|c|c|c|c|c|}
\hline & & Total & Without fracture & With fracture & $\mathbf{p}$ \\
\hline \multicolumn{2}{|l|}{ Total, N } & 250 & 222 & 28 & \\
\hline \multicolumn{2}{|c|}{ Females, $N(\%)$} & $229(92)$ & $203(91)$ & $26(93)$ & 0.574 \\
\hline \multirow[t]{4}{*}{ Ethnicity } & Caucasian, N (\%) & $130(52)$ & $114(52)$ & $16(57)$ & \multirow{4}{*}{0.569} \\
\hline & Afro-Caribbean, $\mathrm{N}(\%)$ & $62(25)$ & $56(25)$ & $6(21)$ & \\
\hline & Asian, $\mathrm{N}(\%)$ & $45(18)$ & $39(18)$ & $6(21)$ & \\
\hline & Other, $\mathrm{N}(\%)$ & $12(5)$ & $12(5)$ & $0(0)$ & \\
\hline \multicolumn{2}{|c|}{ Age SLE diagnosis(y), median (IQR) } & $27(20)$ & $27(18)$ & $36(16)$ & 0.009 \\
\hline \multicolumn{2}{|c|}{ DEXA osteoporosis, N (\%) } & $40(16)$ & $30(14)$ & $10(36)$ & 0.006 \\
\hline \multicolumn{2}{|c|}{ Age at $1^{\text {st }}$ fracture $(y)$, mean $\pm S D$} & N/A & $\mathrm{N} / \mathrm{A}$ & $51 \pm 16$ & N/A \\
\hline \multicolumn{2}{|c|}{ Ever treatment with steroids, $\mathrm{N}(\mathrm{\%}$ ) } & $235(94)$ & $209(94)$ & $26(93)$ & 0.519 \\
\hline \multicolumn{2}{|c|}{ Average daily dose PDN(mg), median (IQR) } & $6.20(3.13)$ & $6.23(3.16)$ & $5.36(3.40)$ & 0.127 \\
\hline \multicolumn{2}{|c|}{ Gumulative dose PDN(g), median (IQR) } & $21.68(22.03)$ & $20.96(21.08)$ & $25.19(20.43)$ & 0.229 \\
\hline \multicolumn{2}{|c|}{ Body mass index, median (IQR) } & $24(6)$ & $24(6)$ & $23(6)$ & 0.440 \\
\hline \multicolumn{2}{|c|}{ Smokers, N (\$) } & $34(27)$ & $29(26)$ & $5(33)$ & 0.385 \\
\hline \multicolumn{2}{|c|}{ Vitamin D deficiency, $\mathrm{N}(\%)$} & $27(11)$ & $22(10)$ & $5(18)$ & 0.167 \\
\hline \multicolumn{2}{|c|}{ Vitamin D supplement, $\mathrm{N}(\%)$} & $232(93)$ & 204 (92) & $28(100)$ & 0.109 \\
\hline \multicolumn{2}{|c|}{ Calcium supplement, $\mathrm{N}(\%)$} & $212(85)$ & $186(84)$ & $26(93)$ & 0.163 \\
\hline \multicolumn{2}{|c|}{ Hyperparathyroidism, N (\$6) } & $6(2)$ & $3(1)$ & $3(11)$ & 0.020 \\
\hline \multicolumn{2}{|c|}{ ESRD, $N(\%)$} & $8(3)$ & $8(4)$ & $0(0)$ & 0.381 \\
\hline \multicolumn{2}{|c|}{ Hyperthyroidism, N (\%) } & $3(1)$ & $3(1)$ & $0(0)$ & 0.699 \\
\hline \multicolumn{2}{|c|}{ Gonadal failure, $N(\%)$} & $4(2)$ & $2(1)$ & $2(7)$ & 0.063 \\
\hline \multicolumn{2}{|c|}{ Rheumatoid arthritis, N (\%) } & $12(5)$ & $9(4)$ & $3(11)$ & 0.139 \\
\hline \multicolumn{6}{|c|}{ Anti-osteoporotic treatment } \\
\hline \multicolumn{2}{|c|}{ Bisphosphonates, $N(\%)$} & $82(33)$ & $60(27)$ & $22(79)$ & $<0.001$ \\
\hline \multicolumn{2}{|c|}{ Denesumpab, N (\%) } & $3(1)$ & $1(0.5)$ & $2(7)$ & 0.034 \\
\hline \multicolumn{2}{|c|}{ Teriparatide, $N(\%)$} & $2(1)$ & $0(0)$ & $2(7)$ & 0.012 \\
\hline \multicolumn{2}{|c|}{ Strontium canelate, N (96) } & $2(1)$ & $0(0)$ & $2(7)$ & 0.012 \\
\hline \multicolumn{2}{|c|}{ Baloxifen, N (\%) } & $2(1)$ & $1(0.5)$ & $1(4)$ & 0.212 \\
\hline \multicolumn{2}{|c|}{ Hormonal replacement therapy, $\mathrm{N}$ (\$) } & $4(2)$ & $3(1)$ & $1(4)$ & 0.380 \\
\hline
\end{tabular}

SLE: Systemic lupus erythematosus; PDN: prednisolone; ESRD: End-stage renal disease

\section{P147 NEUROPSYCHIATRIC MANIFESTATIONS AND MENTAL DISORDERS, A COMPLEX SPECTRUM OF HETEROGENEOUS DISEASE: A DESCRIPTIVE COHORT STUDY}

Roxana González-Mazarío, Jorge Juan Fragío Gil, José Ivorra Cortés, Elena Grau-García, Luis González-Puig, Francisco Miguel Ortiz Sanjuan, Samuel Leal-Rodriguez, Isabel MartínezCordellat, Rosa Negueroles-Albuixech, José Eloy Oller-Rodríguez, Marta De-la-RubiaNavarro, Inmaculada Chalmeta-Verdejo, Cristina Alcañiz-Escandell, Cristóbal Pavez-Perales, Elvira Vicens-Bernabeu, Carmen Nájera-Herranz, Inés Cánovas-Olmos, José Andrés RománIvorra. Rheumatology Dept., Hospital La Fe, Valencia, Spain

\subsection{6/lupus-2020-eurolupus. 190}

Background Neuropsychiatric manifestations in patients with systemic lupus erythematosus (SLE), termed neuropsychiatric SLE (NPSLE), involve a wide variety of neurological and psychiatric manifestations with a complex approach. The aim of this study was to determine the prevalence of mental disorders and neuropsychiatric involvement in a group of patients with SLE and to examine the relationship with other clinical manifestations.
Methods A single center, retrospective, case control study was including patients 18 years and older diagnosed with SLE in a tertiary hospital. Clinical and demographical variables were collected. NPSLE was defined by classification criteria, and others minor nonspecific NPSLE manifestations (depression, anxiety, dizziness) were collected. Statistical analysis was carried out using $\mathrm{R}$ software.

Results From a total of 66 patients 24.2\% (16 patients) had at least one mental disorder or neuropsychiatric manifestation. The most frequently reported was depression $(n=7,43.8 \%)$, dizziness $(n=5 ; 31,2 \%)$; headache $(n=4 ; 25 \%)$; insomnia $(n=2 ; 12.5 \%)$ and cognitive impairment $(n=2 ; 12.5 \%)$. Brain MRI nonspecific findings were reported in 2 patients $(12.5 \%)$. ANA was positive in all cases. The prevalence of anti-Rib-P was very low, only present in one patient (1.5\%). 8 patients (12.1\%) had secondary antiphospholipid syndrome (APS). Associations with APS, other manifestations or corticosteroid use were not statistically significant.

Conclusions There is a low prevalence of severe neuropsychiatric syndromes in our cohort. Almost $1 / 4$ of our cohort had 
at least one mental disorder or neuropsychiatric manifestation, the most frequently reported was depression.

\section{P148 A STUDY OF DISEASE PROFILE OF ADULT AND JUVENILE LUPUS PATIENTS AT DISEASE ONSET AT TERTIARY CARE CENTRE OF NORTHERN INDIA}

${ }^{1}$ Neeraj Jain, 'Lalit Duggal, ${ }^{2}$ Sujata Sawhney, ${ }^{2}$ Manjari Agarawal, 'Jeet Kumar Patel, ${ }^{1}$ Mayank Gupta. ${ }^{1}$ Dept. of Rheumatology, Sir Ganga Ram Hospital, New Delhi; ${ }^{2}$ Dept. of Pediatric Rheumatology, Sir Ganga Ram Hospital, New Delhi, India

\subsection{6/lupus-2020-eurolupus. 191}

Background Systemic Lupus Erythematosus (SLE) is a chronic autoimmune disease. It may affect adults and paediatric patients and may have different organ involvement at onset of disease.

Objectives To study disease profile of 100 adult and paediatric SLE patients at disease onset to find any significant difference in organ involvement in both cohorts.

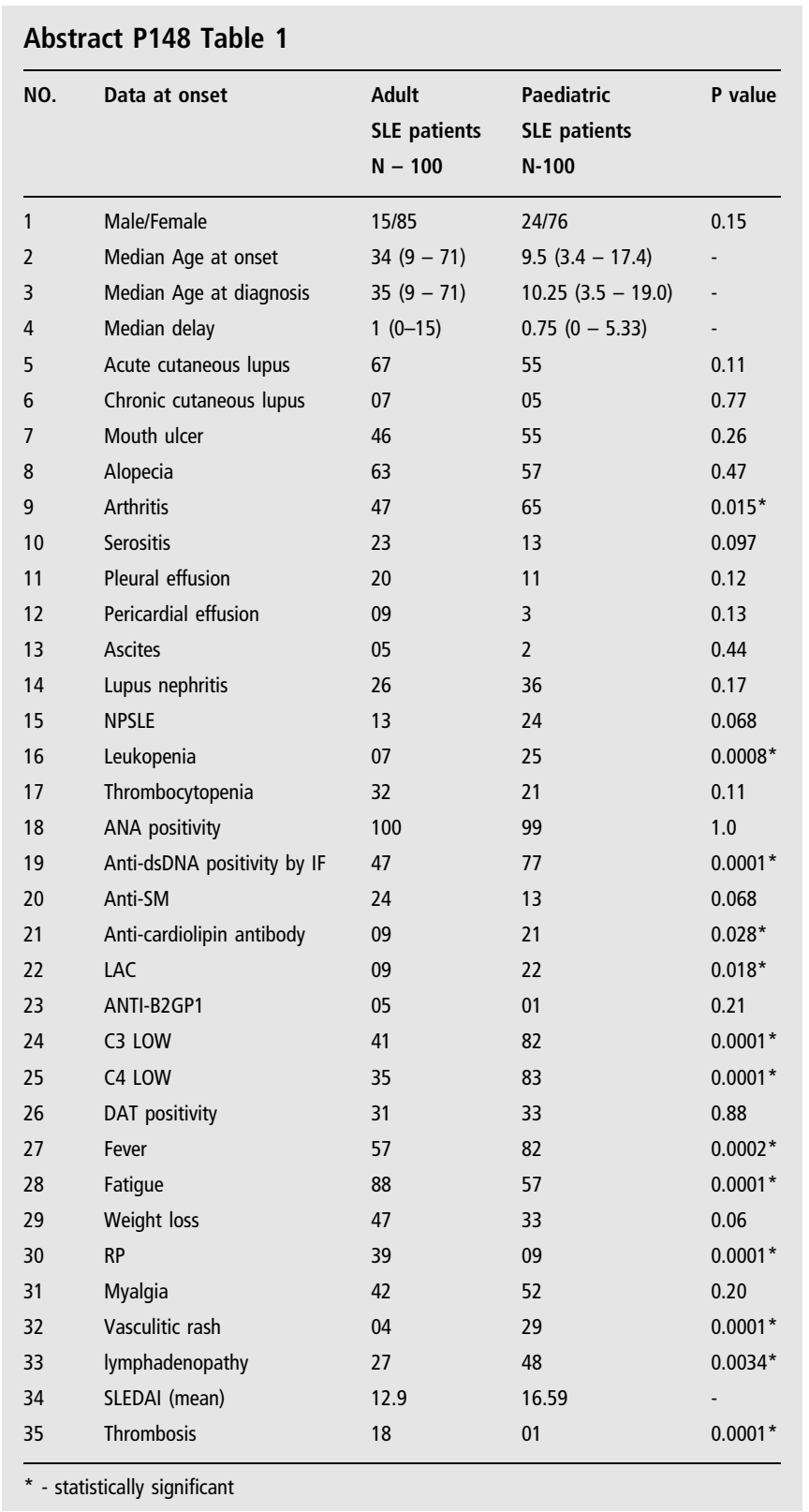

Method 100 adult and 100 paediatric patients who classified SLE-SLICC criteria were recruited in study after taking consent at tertiary care centre in northern India. Demographic data and clinical profiles were recorded. Fisher's test was used to find $\mathrm{p}$ value and $\mathrm{p}$ value less than 0.05 was taken as statistical significance.

Results Out of 100 patients, females were $85 \%$ in adult cohort Vs $76 \%$ in paediatric cohort. Median delay in diagnosis was more with adult than paediatric cases. Lupus nephritis, mouth ulcers, NPSLE was common in paediatric SLE patients. In adult cohort, there was significant association for fatigue, $\mathrm{RP}$, and thrombosis.

Conclusion Major organ involvement was frequent in adult patients while arthritis, leukopenia, low complements, more positivity of anti-dsDNA, APLA antibodies positivity were significantly common in paediatric cases.

\section{P149 ASSOCIATION BETWEEN GEOGRAPHIC AND CLIMATOLOGICAL CONDITIONS AND CUTANEOUS MANIFESTATIONS IN LUPUS PATIENTS FROM THE SPANISH RHEUMATOLOGY SOCIETY LUPUS REGISTRY COHORT}

${ }^{1}$ Raúl Menor-Almagro, ${ }^{2}$ Alejandro Muñoz, ${ }^{3}$ ñigo Rúa-Figueroa, ${ }^{4}$ María Auxiliadora MartínMartínez, ${ }^{5}$ Alejandro Olivé, ${ }^{6}$ María Galindo, ${ }^{7}$ Jaime Calvo-Alén, ${ }^{8}$ Antonio Fernández-Nebro, ${ }^{9}$ Javier López-Longo, ${ }^{10}$ Mariano Andrés, ${ }^{11}$ Eva Tomero, ${ }^{12}$ Esther Uriarte, ${ }^{13}$ Mercedes Freire, ${ }^{14}$ Javier Narváez, ${ }^{15}$ José María Pego-Reigosa, on behalf of RELES-SER. ${ }^{1}$ Rheumatology, Hospital Jerez, Jerez; ${ }^{2}$ Rheumatology, Hospital Virgen del Rocío, Sevilla; ${ }^{3}$ Rheumatology, Hospital Doctor Negrín, Las Palmas GC; ${ }^{4}$ Research Unit, Sociedad Española de Reumatología, Madrid; ${ }^{5}$ Rheumatology, Hospital Germans Trias i Pujol, Badalona; ${ }^{6}$ Rheumatology, Hospital 12 de Octubre, Madrid; ${ }^{7}$ Rheumatology, Hospital Txagorritxu, Vitoria; ${ }^{8}$ Rheumatology, Hospital Regional Universitario Málaga, Málaga; ${ }^{9}$ Rheumatology, Hospital Gregorio Marañón, Madrid; ${ }^{10}$ Rheumatology, Hospital Alicante, Alicante; ${ }^{11}$ Rheumatology, Hospital La Princesa, Madrid; ${ }^{12}$ Rheumatology, Hospital Donostia, Donostia; ${ }^{13}$ Rheumatology, Hospital Juan Canalejo, A Coruña; ${ }^{14}$ Rheumathology, Hospital Bellvitge, Barcelona; ${ }^{15}$ Hospital Meixoeiro, Vigo, Spain

\subsection{6/lupus-2020-eurolupus. 192}

Background/Purpose Ultraviolet radiations act by modifying DNA in sun-exposed skin of lupus patients. We develop a study to analyze the association between climatological conditions and cutaneous manifestations in systemic lupus erythematosus (SLE).

Methods Patients data from Spanish Rheumatology Society Lupus Registry (RELESSER) cohort were retrospectively analyzed for presence of cutaneous lesions (alopecia, photosensitivity, malar rash, discoid lesions, oral ulcers and subacute lesions). We included patients who were assessed in rheumatology services from January 2011 to December 2012. Data of climatological conditions throughout the Spanish geography were provided by the Spanish Meteorological Agency.

Results A total of 2919 patients were included, 87.3\% female. Others biological and clinical data are showed in table 1 . In the multivariable model, positive associations were observed between coastal regions OR $1.470 \quad(95 \%$ CI:1.080-2.001 $\mathrm{p}=0,014)$, anti-DNA OR $1.806 \quad(95 \%$ CI:1.276-2.556, $\mathrm{p}=0.001)$, antiphospholipids antibodies OR $1.428 \quad(95 \%$ CI:1.093-1.864 p=0.009), serositis OR 1.557 (95\% CI:1.181$2.053 \mathrm{p}=0.002)$ and arthritis OR 1.804 (95\% CI:1.258-2.587 $\mathrm{p}=0,001)$. Negative associations were observed between females OR 0.412 (95\% CI:0.284-0.599, p=0.000) and antimalarial drugs OR 0.469 (95\% CI:0.327-0.671, p=0.000).

Conclusion Although the influence of global and ultraviolet radiations on the development of cutaneous lesions in SLE 